\title{
THE CHANGES IN THE HIPPOCAMPUS OF YOUNG RATS INTOXICATED WITH FLUORIDE AND LEAD
}

\author{
$\mathcal{B} \mathcal{Y}$ \\ Irene Atef Fawzy, Eman Ismail Hasan, Maggie Maher Ramzy* \\ And Rehab Ahmed Refai** \\ Departments of Forensic Medicine and Toxicology, Biochemistry* and Histology** \\ Faculty of Medicine, Minia University
}

\begin{abstract}
This study was designed to verify the effects of fluoride (F) or lead (Pb) or both together on blood fluoride and lead levels, alanine transaminase (ALT), asparrate transaminase (AST), and acetylcholine esterase activities as well as the morphological changes by light microscope and immunohistochemical study of caspase 3 in hippocampus of offspring rats at postnatal week 6 and 8. Sixty albino rats (30 males and 30 females) were used in this study. After mating, twenty-four pregnant female rats were randomly divided into 4 groups of six each. Beginning with day of delivery the first group served as controls and they received distilled water, the second group received sodium fluoride ( $\mathrm{NaF}$ ) in a dose of $150 \mathrm{mg} / \mathrm{L}$, the third group was given lead acetate $300 \mathrm{mg} / \mathrm{L}$. Rats of the fourth group received $\mathrm{NaF} 150 \mathrm{mg} / \mathrm{L}+$ lead acetate $300 \mathrm{mg} / \mathrm{L}$. The rats' offspring divided into 4 groups (10 rats in each group) at 3 weeks post natal ate and drank by themselves and were given the same treatment as parental generation. Results showed that the activities of the enzymes in all groups were significantly decreased in comparison with the control group at both 6 and 8 weeks. Both the fluoride level in $F$ and $F+p b$ groups, and the lead level in the lead and $F$ + pb groups were significantly higher than the control group. At 6 weeks, morphological study of hippocampal sub-regions of the three treated groups demonstrated degenerated neurons and the immunopositive cells in the cornu ammonis-3 (CA3) zone, but at 8 weeks, they became in the CAI zone as well in Fluoride group, in most of the pyramidal neurons and granular cell layer of dentate gyrus (DG) in lead and Fluoride+lead group. In conclusion, excessive intakes of $F$ and lead either alone or in combination during the early developing stages of life affect the hippocampus biochemically, histopathologically and immunohistochemically.
\end{abstract}

\section{INTRODUCTION}

Lead $(\mathrm{pb})$ is a naturally occurring element that has been used almost since the beginning of civilization. The major environmental sources of metallic lead and its salts are paint, auto exhaust, food, water and folk remedies as use of kohl (AbdelMaaboud et al., 2003). Lead contaminating drinking water is most often a problem in houses that are either very old or very new. The source of lead in such water is 
most likely pipe or solders plumbing (Habal, 2002). Egyptian children under the age of 5 have the highest $\mathrm{Pb}$ blood level because of increased gastrointestinal absorption and exposure through behaviors such as playing outdoors and increased hand-to-mouth activity (Abdel-Maaboud et al., 2005).

$\mathrm{Pb}$ is a highly neurotoxic metal that causes functional and structural abnormalities in the brain. Canfield et al. (2003) reported that the blood $\mathrm{Pb}$ level even below the current safety standards still showed a threat to intelligence of children.

Fluoride (F) widely exists in environment with a significant increase in recent years in body burden accumulation (Wang, 2007). Internal exposure to fluoride due to diet including food, water, beverages, tea, fluoride-containing dental products like tooth paste and fluoride supplements (Doull et al., 2006). Additionally, industrial pollution and coal burning have also been reported to be major sources of internal exposure ( $\mathrm{Li}$ et al., 2003). Xinag et al. (2003) found that drinking water with greater fluoride levels adversely affect the development of children's intelligence.

Reports on the effect of sodium fluoride $(\mathrm{NaF})$ on rat brain and other tissues (Bhatnagar et al., 2006) and on neuronal cell bodies in the hippocampus suggest that excess fluoride intake has CNS effects
(Bhatnagar et al., 2002). Interestingly, fluoride has been reported to increase the accumulation of neurotoxicant $\mathrm{Pb}$ in the body (Masters et al., 2000).

The hippocampus is one of the brain structures making up the limbic system. It plays important roles in the consolidation of information from short term memory to long term memory and spatial navigation (Bayer, 1985). Hippocampus has been postulated to be one of the target sites attacked by lead (Sharifi et al.2002) and fluoride (Bouaziz et al.2007).Consequently, the aim of this research was to investigate the toxic effect of fluoride and lead either alone or in combination on hippocampus of suckling rats.

\section{MATERIALS AND METHODS}

\section{Chemicals:}

Lead acetate was obtained from Adwic Co.; sodium fluoride was obtained from LOBA Chemie, private (PVT), limited (LTD). AST and ALT kits were obtained from Biodiagnostic, Egypt and Acetylchloinestrase Assay kit was obtained from BioAssay System.

\section{AnimaIs:}

Sixty albino rats ( 30 males and 30 females) weighing 200-250 gm were used in this study. They were housed in animal cages with food and water ad libitum with standard laboratory conditions. 
The animals were acclimatized to the laboratory conditions for 1 week before the experiment began. The study design was performed in accordance with the guide of the care and use of laboratory animals approved by the committee of Minia University. Female rats were caged overnight with males and the presence of spermatozoa in the vaginal smear was taken as an indicator of days 0 of pregnancy. Pregnant female rats were selected and housed individually.

Twenty-four pregnant female rats were randomly divided into 4 groups of six each. Beginning with day of delivery the first group served as controls and they received distilled water, the second group received sodium fluoride $(\mathrm{NaF})$ in a dose of $150 \mathrm{mg} / \mathrm{L}$, the third group was given lead acetate $300 \mathrm{mg} / \mathrm{L}$. Rats of the fourth group received $\mathrm{NaF} 150 \mathrm{mg} / \mathrm{L}+$ lead acetate $300 \mathrm{mg} / \mathrm{L}$ (Niu et al., 2009).

The rats' offspring received only the maternal milk for the first postnatal 2 weeks then gradually began to feed and drink water by themselves beside the maternal milk. At 3 weeks post natal, the offspring ate and drank by themselves and they were divided into 4 groups (10 rats in each group) and were given the same dose as parental generation starting from the third postnatal week. At 6,8 post natal weeks, rats were anaesthetized with ether. The hippocampus was removed and part of it was put aside for histopathological and immunohistochemical evaluation then the remaining part was quickly weighted, homogenized in phosphate buffer $(0.1 \mathrm{M}, \mathrm{pH} 7.5)$. The tissue homogenate was centrifuged for $10 \mathrm{~min}$ at $10000 \mathrm{rpm}$ at $4^{\circ} \mathrm{C}$ and the supernatant was used for the biochemical assays

\section{Enzymes assay:}

Alanine aminotransferase (ALT) and aspartate aminotransferase (AST) were assessed in tissue homogenate according to the method of Wilkinson et al. (1972). These enzymes were detected by spectrophotometer at $505 \mathrm{~nm}$. The two enzymes activities were calculated from a standard gxaph and expressed as $\mathrm{U} / \mathrm{mg}$ protein.

\section{Determination of acetylcholinesterase activity:}

The acetylcholinesterase (AChE) activity was measured immediately in tissue homogenates according to the method of Ellman et al. (1961), in which thiocholine produced by the action of acetylcholinesterase forms a yellow color with 5,5'dithiobis (2-nitrobenzoic acid). The intensity of the product color, measured at 412 $\mathrm{nm}$, is proportionate to the enzyme activity in the sample. Activities were expressed as U/g protein (Wilson B. W. et al., 1996)

\section{Blood lead level:}

Blood samples $(2 \mathrm{ml})$ were drawn from each pub in heparinized tubes. The blood 
lead level was measured by graphite furnace at atomic absorption spectrometry and the quality control procedure for the assessment of lead exposure was performed.

\section{Blood fluoride level:}

Plasma samples are used for determination of fluoride concentration. Equal amount of TISAB II buffer was added to the samples. All samples were mixed using magnetic stirrer throughout the measurements and ion selective electrode system (Orion Research Corporation, USA) was used to measure the fluoride concentration.

\section{Histopathological examination:}

The removed hippocampus was processed for paraffin embedding by standard methods and sections of $6 \mu \mathrm{m}$ thicknesses were deparaffinized with xylene and stained with hematoxylin-eosin to be viewed by light mi-croscopy (Bancroft et al., 2002).

\section{Immunohistochemical stains:}

Immunohistochemical staining was performed using polyclonal rabbit anti active caspase 3 antibody (Transduction laboratories) according to previously published protocol (Côté et al., 1993). Briefly, sections were deparafinized, hydrated then washed in $0.1 \mathrm{M}$ phosphate buffer saline (PBS). Sections were then treated with trypsin $0.01 \%$ for 10 minutes at $37^{\circ} \mathrm{C}$ then washed with PBS for 5 minutes. Endogenous peroxidases were quenched by treatment with $0.5 \% \mathrm{H}_{2} \mathrm{O}_{2}$ in methanol and non-specific binding was blocked in normal goat serum diluted 1:50 in 0.1M PBS. Tissues were incubated in the primary antibodies (caspase-3; 1:1000, Sigma pharmaceutical Company) overnight at $4^{\circ} \mathrm{C}$. Tissues were washed and incubated in biotinylated goat anti-rabbit secondary antibody (1:2000, Thermoscientific,USA) for 30 minutes. Following further 30 minutes incubation in Vectastain $A B C$ reagent, the substrate amino ethylcarbazole (AEC) was added for 6 minutes, this substrate gives red colour at the immunoreactive sites (Mabuchi et al., 2001).

\section{RESULTS}

AST and ALT activities of hippocampus of rats' offspring:

It can be seen from Table 1, that the activities of AST and ALT in hippocampus of rats offspring exposed to fluoride or lead alone or both for 6 and 8 weeks were significantly decreased $(p<0.05)$ compared to the control group. Moreover, a significant decrease in AST activity occurred in rats exposed to $\mathrm{F}$ or $\mathrm{pb}$ or both from 6 to 8 weeks. While, a significant decrease occurred in ALT activity in rats hippocampus of $\mathrm{F}$ or $\mathrm{pb}$ or both from 6 to 8 weeks. 
Acetyl choline esterase activity of hippocampus of rats' offspring :

Table 2 shows that $\mathrm{AChE}$ activity in hippocampus of rats offspring in $\mathrm{F}$ or $\mathrm{pb}$ or both groups were significantly decreased $(\mathrm{p}<0.05)$ in comparison with the control group at both 6 and 8 weeks of the exposure. However, there was a significant increase in $\mathrm{AChE}$ activity in $\mathrm{F}$ or $\mathrm{F}+\mathrm{Pb}$ groups from week 6 to 8 but a significant decrease in its level was observed in $\mathrm{pb}$ group from weeks 6 to 8 .

\section{Blood fluoride and lead levels of rats'} offspring :

The blood levels of lead and fluoride in offspring rats at 6 and 8 weeks were shown in Table 3. At 6 weeks, the fluoride level in $\mathrm{F}$ and $\mathrm{F}+\mathrm{pb}$ groups were significantly higher $(p<0.05)$ than the control group. The lead level in the lead and F+ $\mathrm{pb}$ groups were significantly higher $(\mathrm{p}<0.000)$ than the control group. From 6 to 8 weeks, there was a significant increase in fluoride level in offspring rats group exposed to $F$ and a non significant change in its level in $\mathrm{F}+\mathrm{pb}$ group from 6 to 8 weeks. The lead level of lead and $\mathrm{F}+\mathrm{Pb}$ treated rats showed significant increase from weeks 6 to 8 of treatment.

One way ANOVA analysis shows statistically significant difference $(p<0.000)$ of AST, ALT, AChE activities, blood lead and plasma fluoride levels among the studied groups at both 6 and 8 weeks of exposur.

\section{Histological examination of rats' hip-} pocampus :

The pyramidal neurons of $\mathrm{CA} 3$ zone of the control group were densely packed and characterized by vesicular nuclei with prominent nucleoli (fig. 1A). In the six weeks of both $F$ and lead treated groups, few degenerated neurons were noticed in the cornu ammonis-3 (CA3) zone (fig.1B and fig. 1C). While in the eight weeks of $F$ treated group, few degenerated neurons were seen in CA1 zone as well (fig.2B). In the eight weeks of lead treated group, most of the pyramidal neurons became degenerated. They became shrunken with darkly stained cell body and pyknotic nuclei (fig. 2C). The six weeks of both $\mathrm{F}$ and lead treated groups, showed many degenerated neurons in the $\mathrm{CA} 3$ zone (fig. 1D). After eight weeks of both $\mathrm{F}$ and lead treatment, most of the pyramidal neurons of the CA1, CA2, CA3 and CA4 zones became degenerated. Also the granular cells of the dentate gyrus (DG) became apoptotic (fig.2D).

\section{Immunohistochemical study for cas-} pase 3 :

Immunohistochemical study for caspase 3 of the control group showed few pyramidal neurons with faint cytoplasmic staining (fig. $3 \mathrm{~A}$ and fig. $4 \mathrm{~A}$ ). In the six weeks of $\mathrm{F}$ treated group, few cell of cornu ammonis-3 (CA3) zone showed positive cytoplasmic expression (Fig.3B). Immunopositive cells were also observed in 
the cornu ammonis-1 (CA1) zone after eight weeks of treatment (fig. 4B). In the six weeks of lead treated group, few cells of $\mathrm{CA} 3$ zone showed positive cytoplasmic expression (Fig. 3C). In the eight weeks of lead treated group, nearly all the pyramidal cells became immunopositive. Some granular neurons became immunopositive (Fig. 4C). High expression was noticed in pyramidal neurons of $\mathrm{CA} 3$ and $\mathrm{CA} 4$ zones of the six weeks of both $\mathrm{F}$ and lead treated groups (Fig. 3D). In the eight weeks of both $\mathrm{F}$ and lead treated groups, nearly all the pyramidal cells and the granular neurons became immunopositive. Some immunopsitive cells showed cytoplasmic expression, others showed nuclear expression (Fig. 4D).

\section{DISCUSSION}

Fluoride is an essential trace element but the beneficial range is so narrow that health may be influenced adversely if excessive fluoride is supplied (Shanthakumari et al., 2004). Lead is a ubiquitous pollutant in the ecosystem and is recognized by toxic effects on several organs and systems, particularly the central nervous system during early development (ATSDR, 2005).

To confirm if the biochemical effects are indeed related to body fluoride and lead burdens, we determined plasma fluoride and blood lead concentrations. The present study showed that lead levels at both 6 and 8 weeks were significantly increased in the blood of offspring rats of $\mathrm{Pb}$ or $\mathrm{Pb}+\mathrm{F}$ groups in comparison with the control group. This finding is in agree with Liu et al. (2010). The significant lead levels in blood reflects the free access of the metal as a result of penetration of this metal from the blood to the brain, which is consistent with previous studies (Garci'aArenas et al.,1999 and $\mathrm{Yu}$ et al., 2008).At both 6 and 8 weeks of $\mathrm{F}$ treatment to the rats offspring alone or in combination with lead, showed significant higher blood plasma $F$ level which in accordance with Chouhan et al.(2009) and Zhu et al. (2011).

AST and ALT are native brain enzymes existing in cytosolic and mitochondrial forms. AST and ALT play important roles in the synthesis of endogenous glutamate to compensate for its loss and to maintain overall metabolic balance in the brain (Yudkoff et al., 1991). In this study, the activities of ALT and AST in the hippocampus was significantly decreased at both 6 and 8 weeks of exposure to $F$ or $\mathrm{pb}$ or both compared to the control group.. Moreover, a significant decrease in AST activity and a significant decrease in ALT activity occurred in rats exposed to $\mathrm{F}$ or $\mathrm{pb}$ or both from 6 to 8 weeks but still significantly lower than the control group. The different fluctuations of AST and ALT may be due to the distinct toxic mechanism of 
these two elements. This is in agree with Niu et al. (2009) who showed that the activities of AST and ALT in treatment groups were significantly inhibited which suggests that disturbance of glutamate metabolism in hippocampus may be one of the mechanisms by which $\mathrm{F}$ and/or $\mathrm{Pb}$ influence the intelligence and central nervous system.

$\mathrm{AChE}$ is the key enzyme in control of cholinergic transmission in the central and peripheral nervous system and brain cholinesterase activity are important to maintain normal brain physiological function and learning-memory ability (Liu et al., 1999). The present investigation revealed that $\mathrm{F}$ or $\mathrm{F}^{+} \mathrm{Pb}$ treated rats showed a significant decrease in hippocampus $\mathrm{AChE}$ activities at both 6 and 8 weeks in accordance with $W u$ et al., (2006). This decrease could be due to loss of neuron cell bodies in the hippocampus (Bhatnagar et al., 2002), loss of synaptic structures or inhibition of enzyme activity (Zhang etal., 2001). A significant increase in $\mathrm{AChE}$ activity occurred in $\mathrm{F}$ or $\mathrm{F}^{+} \mathrm{Pb}$ groups from week 6 to 8 . This is in line with Hong et al. (2005) and could be explained by Sun et al. (2000) who revealed that severe fluorosis may exert a stimulatory effect on the activity of AChE.

In the present study, lead caused a significant decrease in hippocampus AChE activity in both $\mathrm{Pb}$ or $\mathrm{F}^{+} \mathrm{Pb}$ treated off- spring rats at both 6 and 8 weeks compared to the control group and a significant decrease in its level was observed in $\mathrm{Pb}$ group from weeks 6 to 8 . These results are in agree with Reddy et al. (2003).Thus, $\mathrm{Pb}$-exposure may affect $\mathrm{AChE}$ activity in brain areas controlling learning and cognitive behavior. Our findings confirm the earlier findings that lead exposure mainly affects the cholinergic system by reducing $\mathrm{AChE}$ release as lead competes with calcium $\left(\mathrm{Ca}^{2+}\right)$, which may account for the disruption of the cholinergic function and alteration in the other transmitter systems (Cooper et al., 1984). Other explanation by Tsakiris et al. (2000) was that the activity of $\mathrm{AChE}$ is decreased on exposure to free radicals.

To elucidate if fluoride and lead may lead to organ damage, we supported our biochemical results with histopathological observations in the hippocampus. At six weeks, the histopathological findings are correlated with that of Shivarajashankara et al. (2002) who revealed that in the hippocampus of young fluoride intoxicated rats, neurons were shrunken and darkly stained with a small nucleus, and there was a decrease in the cell number. Histological alterations were seen in CA1, CA4, and dentate gyrus (DG) sub-regions of the hippocampus. They reported that the histological changes suggest a toxic effect of high-fluoride intake during the early developing stages of life on the growth, dif- 
ferentiation and subcellular organization of brain ceils in rats. Zhang et al. (2010) indicated that fluorosis could injure the pyramidal cells in the hippocampus CA3 region to some degree. Bhatnagar et al. (2002) reported that light microscopic study of hippocampal sub-regions demonstrated significant number of degenerated nerve cell bodies in the CA3, CA4 and Dg areas of sodium fluoride administered female mice.

With light microscope, few degenerated neurons were noticed in the CA3 zone in the six weeks lead treated group, while in eight weeks treated group most of the pyramidal neurons became degenerated. Selvín-Testa, (1994) observed hypertrophic astrocytes in the hippocampus of chronic lead administration. Impairments of hippocampus caused by lead were at least partly related to the apoptosis induction by lead (Chen et al., 2004).

Caspase 3 is the key figure in apoptosis (Lanshakov et al., 2009). High expression of caspase- 3 in the neonatal brain is associated with intensive fragmentation of DNA, the key sign of apoptosis (Menshanov et al., 2006). This work revealed hippocapal expression of caspase 3 and apoptotic cells among the treated groups. Zhang et al., (2007) suggested that fluoride could cause oxidative stress and apoptosis in rat hippocampal neurons, contributing to its neurotoxicity. Some studies also showed that chronic fluoride may induce oxidative stress leading to generation of free radicals and alterations in antioxidants or reactive oxygen species (ROS) scavenging enzymes, which contribute to tissue damage and have been implicated as potential modulators of apoptosis. The ability of oxidative stress to provoke apoptosis as a result of massive cellular damage has been associated with lipid peroxidation. Disruption of the outer mitochondrial membrane by apoptotic stimuli results in the release of cytochrome $\mathrm{c}$ into the cytoplasm where it initiates a cascade of caspase activation and results in apoptosis (Anuradha et al., 2001).

Selvin-Testa et al.(1991) demonstrated after chronic lead treatment, an increase in the expression of anti-glial fibrillary acidic protein (GFAP) antibody in the hippocampus of the rats offspring. The mechanisms by which lead affects astrocytes are unknown. Probably the astroglial changes induced by lead intoxication produce micro-environmental modifications that may disturb the neuronal function.

In conclusion excessive intakes of $\mathrm{F}$ and lead either alone or in combination during the early developing stages of life affect the hippocampus ALT, AST and AChE activities. The altered morphology and the degenerative changes of the rats' hippo- 
campus suggest the $\mathrm{F}$ and $\mathrm{Pb}$ toxicity and may form the neural basis for impaired learning and memory. The expression of hippocampal caspase-3, following $\mathrm{F}$ and lead indicate apoptotic neuronal cell death in the hippocampus, which makes the hippocampus may be the target for fluoride and lead. 
Table 1: AST and ALT ( $\mathrm{U} / \mathrm{mg}$ protein) activities in hippocampus of rat offsprings among the studied groups (no=10 rats)

\begin{tabular}{|l|c|c|c|c|}
\hline \multicolumn{1}{|c|}{ Parameter } & $\begin{array}{c}\text { Control } \\
\text { group }\end{array}$ & F group & Pb group & $\begin{array}{c}\text { F+pb } \\
\text { group }\end{array}$ \\
\hline AST (6 weeks) & $7.17 \pm 0.09$ & $2.37 \pm 0.23 \mathrm{a}$ & $4.61 \pm 0.07 \mathrm{a}$ & $\begin{array}{c}2.94 \pm \\
0.13 \mathrm{a}\end{array}$ \\
\hline AST (8 weeks) & $7.14 \pm 0.13$ & $1.85 \pm 0.03 \mathrm{ab}$ & $3.34 \pm 0.08 \mathrm{ab}$ & $\begin{array}{c}2.31 \pm \\
0.03 \mathrm{ab}\end{array}$ \\
\hline ALT(6 weeks) & $17.18 \pm 1.42$ & $8.99 \pm 0.12 \mathrm{a}$ & $9.40 \pm 0.70 \mathrm{a}$ & $\begin{array}{c}10.08 \pm \\
0.14 \mathrm{a}\end{array}$ \\
\hline ALT(8 weeks) & $17.14 \pm 0.07$ & $11.42 \pm 0.30 \mathrm{ab}$ & $10.48 \pm 0.03 \mathrm{ab}$ & $\begin{array}{c}11.37 \pm \\
0.06 \mathrm{ab}\end{array}$ \\
\hline
\end{tabular}

$\mathrm{F}=$-luoride, $\mathrm{pb}=$ lead $\quad \mathrm{p}<0.05$ is significant

$\mathrm{a}=$ significant differeocc as regards the comparison of each of $\mathrm{F}, \mathrm{pb}$ and $\mathrm{F}+\mathrm{Pb}$ groups with the control groug

$\mathrm{b}=$ significant difference in each of control, F. $\mathrm{pb}$ and $\mathrm{F}+\mathrm{Pb}$ groups from 6108 weeks of treatment

Table 2: AChE (u/g protein) activities in hippocampus of rats offspring among the studied groups (no $=10$ rats)

\begin{tabular}{|l|l|l|l|l|}
\hline Parameter & Control group & F group & Pb group & F+pb group \\
\hline $\begin{array}{l}\text { AChE (6 } \\
\text { weeks) }\end{array}$ & $100.5 \pm 1.23$ & $1.75 \pm 33.2 \mathrm{a}$ & $59.1 \pm 3.66 \mathrm{a}$ & $39.56 \pm 3.02 \mathrm{a}$ \\
\hline $\begin{array}{l}\text { AChE (8 } \\
\text { weeks) }\end{array}$ & $102.80 \pm 3.22$ & $50.30 \pm 3.12 \mathrm{ab}$ & $39.20 \pm 2.78 \mathrm{ab}$ & $42.60 \pm 2.22 \mathrm{ab}$ \\
\hline
\end{tabular}

$\mathrm{ACh} E=$ Acetylcholine esterase $\quad \mathrm{p}<0.05$ is significant

$\mathrm{a}=$ significant difference as regards the comparison of each of $\mathrm{F}, \mathrm{pb}$ and $\mathrm{F}+\mathrm{Pb}$ groups with the control group $\mathrm{b}=$ significant difference in each of control, $\mathrm{F}, \mathrm{pb}$ and $\mathrm{F}+\mathrm{Pb}$ groups from 6 to 8 weeks of treatment

Table 3: The plasma fluoride $(\mathrm{mg} / \mathrm{l})$ and Blood Lead levels $(\mu \mathrm{g} / \mathrm{dl})$ in rat offsprings among the studied groups (no=10 rats)

\begin{tabular}{|l|l|l|l|l|}
\hline Parameters & Control group & F group & Pb group & F+pb group \\
\hline $\begin{array}{l}\text { Fluoride (6 } \\
\text { weeks) }\end{array}$ & $0.09 \pm 0.01$ & $2.16 \pm 0.05 \mathrm{a}$ & $0.08 \pm 0.03$ & $3.02 \pm 0.26 \mathrm{a}$ \\
\hline $\begin{array}{l}\text { Fluoride }(8 \\
\text { weeks) }\end{array}$ & $0.12 \pm 0.01$ & $3.21 \pm 0.26 \mathrm{ab}$ & $0.09 \pm 0.03$ & $2.73 \pm 0.36 \mathrm{a}$ \\
\hline lead (6 weeks) & $2.54 \pm 0.08$ & $2.55 \pm 0.05$ & $21.39 \pm 0.03 \mathrm{a}$ & $19.74 \pm 0.03 \mathrm{a}$ \\
\hline $\begin{array}{l}\text { Lead }(8 \\
\text { weeks) }\end{array}$ & $2.02 \pm 0.10$ & $2.04 \pm 0.33$ & $23.57 \pm 0.29 \mathrm{ab}$ & $22.20 \pm 0.08 \mathrm{ab}$ \\
\hline
\end{tabular}

$\mathrm{a}=$ significant differesce as regards the comparison of each of $\mathrm{F}, \mathrm{pb}$ and $\mathrm{F}+\mathrm{Pb}$ groups with the control group $\mathrm{b}=$ significant difference in each of control, $\mathrm{F}, \mathrm{pb}$ and $\mathrm{F}+\mathrm{Pb}$ groups from 6 to 8 weeks of treatroent $p<0.05$ is significant 

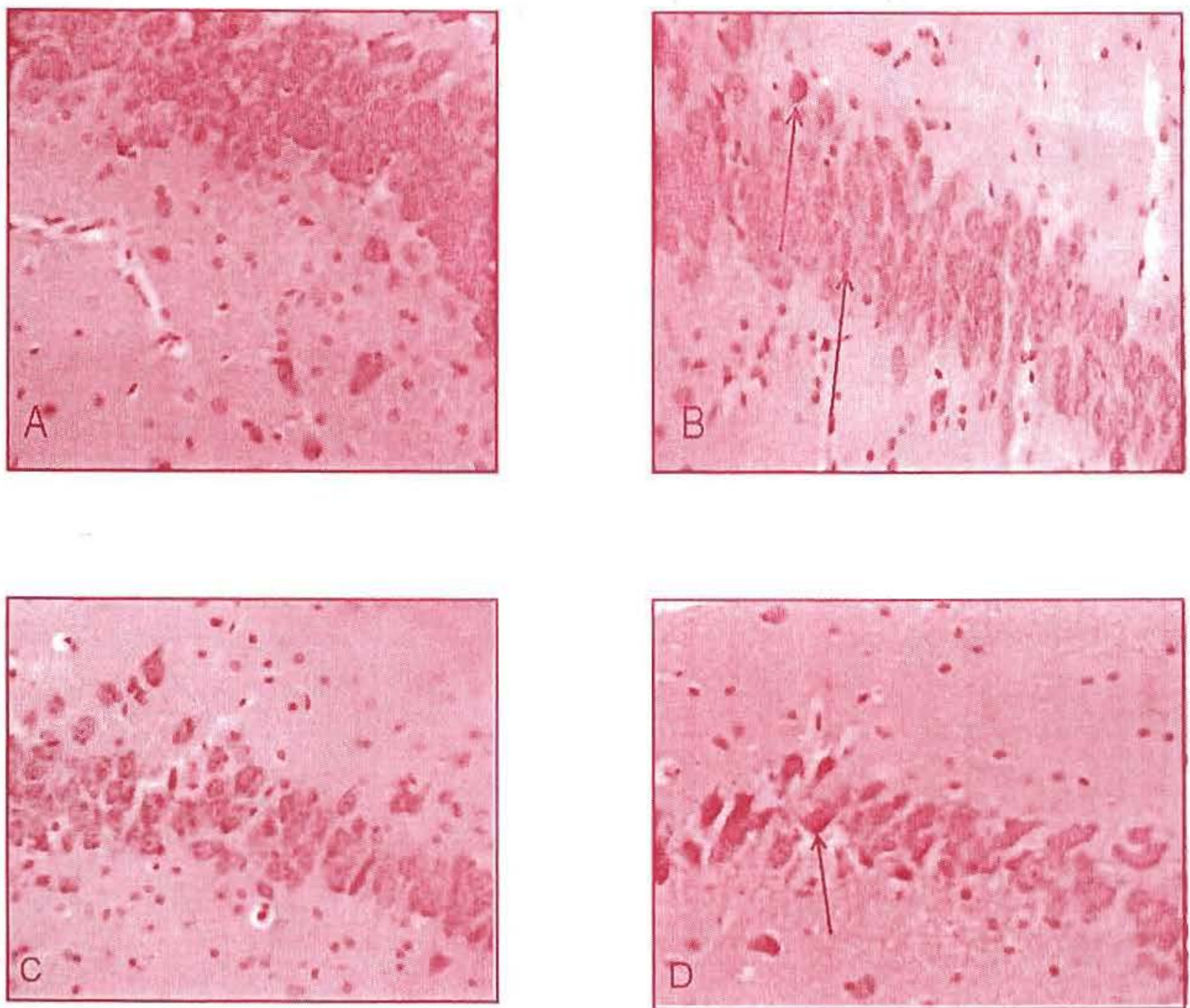

Figure (1): Photomicrograph of pathological changes of the CA3 zone of the hippocampus of $A$ ) the control group showing normal pyramidal neurons of $\mathrm{CA} 3$ zone. B) six weeks $\mathrm{F}$ treated group showing few degenerated neurons (arrows). C) six weeks lead treated group showing few degenerated neurons. D) of six weeks $\mathrm{F}+$ lead treated group showing many degenerated neurons with shrunken, darkly stained cell body with nuclear pyknosis (arrow) (H\&E X400). 

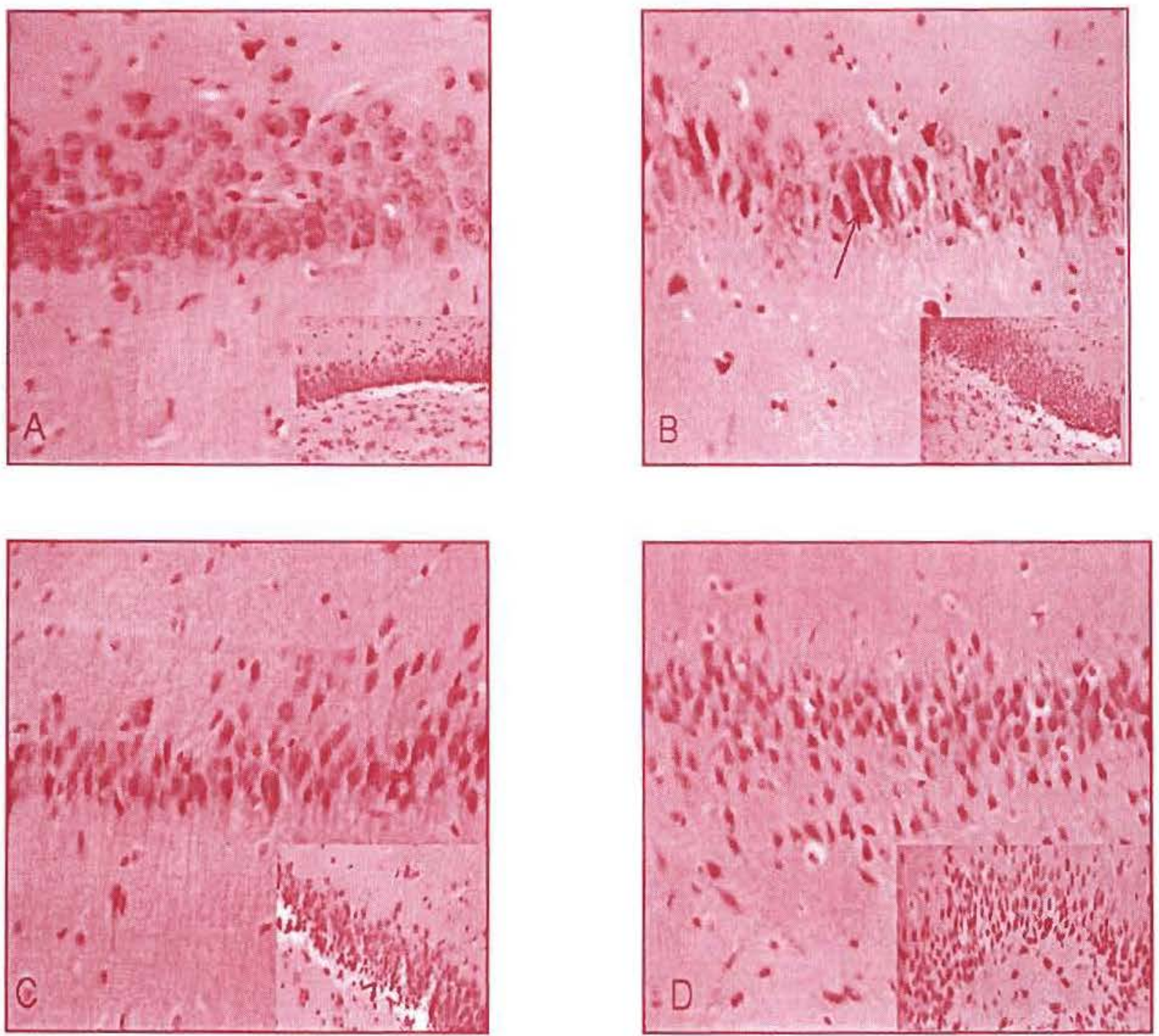

Figure (2): PHotomicrograph of the pathological changes of hippocampus $C A 1$ zone. A)Insets showing the granular cell layer of the DG of the control group showing normal pyramidal neurons and granular neurons (inset).B) eight weeks $\mathrm{F}$ treated group showing few darkly stained degenerated neurons (arrow). Inset showing normal granular cell layer (H\&E X400).C) eight weeks lead treated group showing many darkly stained degenerated pyramidal neurons. Inset showing apoptotic darkly stained granular cells with nuclear pyknosis (arrow head).D) eight weeks F+lead treated group showing the darkly stained degenerated pyramidal neurons. Most of the granular cells assumed apoptotic morphology (inset) (H\&E X400). 

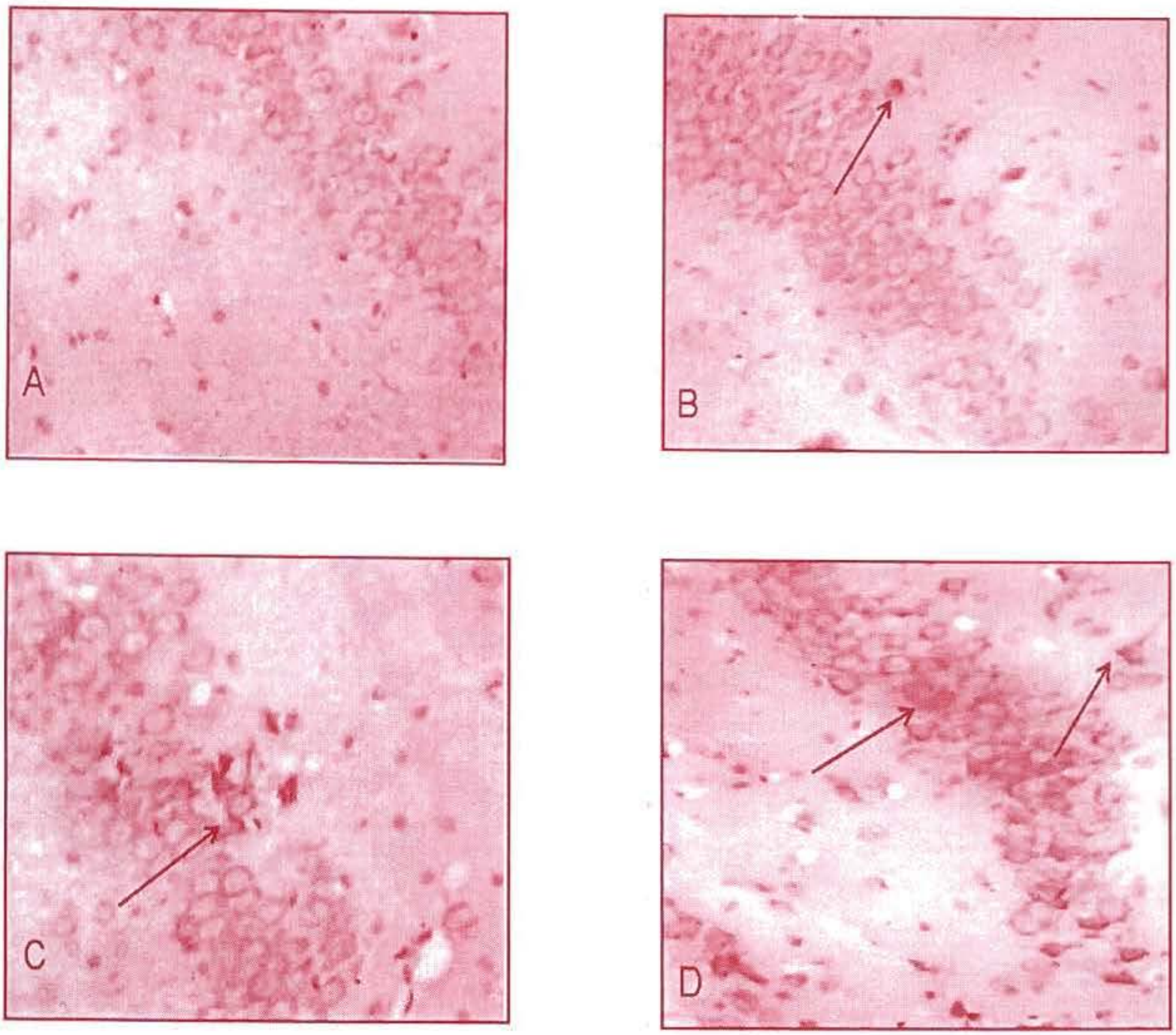

Figure (3): Immunohistochemical localization of caspase 3 in $\mathrm{CA} 3$ of A) control group showing few neurons with faint cytoplasmic staining. B) In six weeks F treated group showing few immunopositive cells of CA3 zone with dense cytoplasmic staining (arrow). C) six weeks lead treated group showing densly stained immunopositive cells of $\mathrm{CA} 3$ zone (arrow). D) six weeks lead $+\mathrm{F}$ treated group showing the high expression among the pyramidal neurons of CA3 and CA4 zones (arrows). It was noticed that in all groups, scattered glial like cells shows positive immunoreactivity (arrow) $(\mathrm{X} 400)$. 

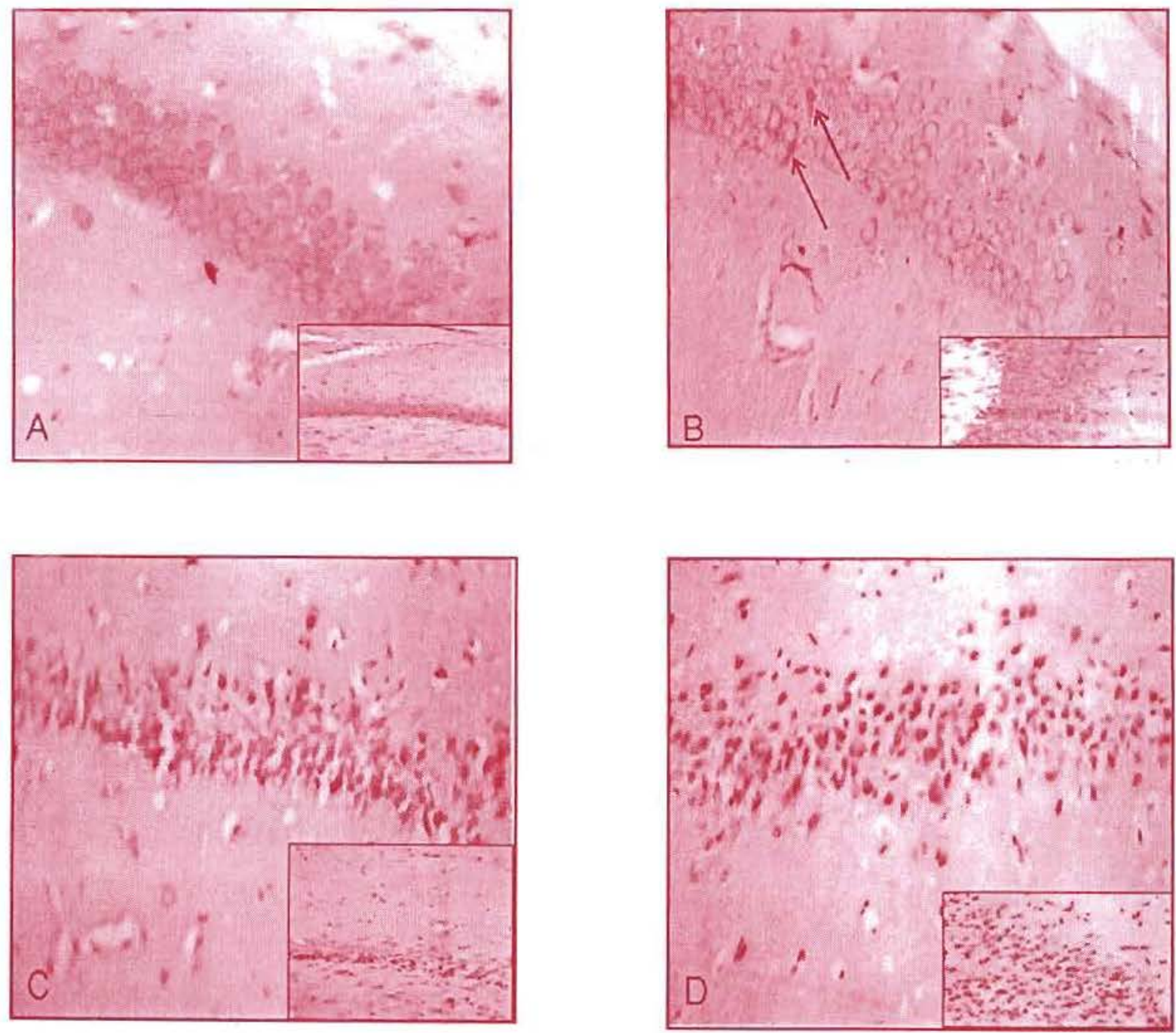

Figure (4): Immunohistochemical localization of caspase 3 in the pyramidal cells of CA1 zone and the granular layer of the DG (insets) of A) control group showing negative expression. B) eight weeks $F$ treated group showing the immunopositive pyramidal cells of CA1 zone (arrow). Negative expression was noticed in the granular cell layer of the DG. C) eight weeks lead treated group showing that most of the pyramidal cells of CA1 zone become immunopositive. Some immunopositive granular cells are shown (inset). D) eight weeks lead+F treated group showing the high expression among the pyramidal neurons and the granular cells of DG (inset). It was noticed that in all groups, scattered glial like cells shows positive immunoreactivity (X400). 


\section{REFERENCES}

Abdel-Maaboud, R. M.; El-Attar, M. M.; Mohamad, N. A.; Ahmed, S. M. and Medhat, A. (2005) : "Lead toxicity in some rural communities in Assuit governorate". Ass. Univ. Bull. Environ. Res., 8: 57-66.

Abdel-Maaboud, R. M.; Shehata, M. M. and Abdel-Maksoud, S. A. (2003): "Histological changes in the kidney and liver of the rabbit as a result of the use of Koh". Alazher Assiut Medical Journal ,1 (2): 9-24.

Anuradha, C. D.; Kano, S. and Hirano, S. (2001) : "Oxidative damage to mitochondria is a preliminary step to caspase-3 activation in fluoride-induced apoptosis in HL-60 cells". Free Radic. Biol. Med., 1: 367.

ATSDR (Agency for Toxic Substance and Disease Register) (2005) : "Toxicological profile for lead". Atlanta, GA : US Department of Health and Humans Services, Public Health Service, Centers for Diseases Control.

Bancroft, J. D.; Stevens, A. and Turner, D. R. (2002) : "Theory and practice of histological techniques". $4^{\text {th }}$ Ed. New York, Churchill Livingstone.

Bayer, S. (1985) : "Hippocampal region", In : Paxinos G (Ed.), The Rat Nervous System Vol1; Forebrain and Mid- brain, New York, Academic Press. pp. 335-352.

Bhatnagax, A.; Rao, P.; Saxena, A.; Bhatnagar, R.; Meena, P.; Barbar, S.; Chouhan, A. and Vima, S. (2006): "Biochemical changes in brain and other tissues of young adult female mice from fluoride in their drinking water". Fluoride, 39: $280-284$.

Bhatnagar, M.; Rao, P.; Shukla, S.; Jain, $S$. and (2002) : "Neurotoxicity of fluoride: evidence of neurodegeneration in hippocampus of female mice Ind". J. Exp. Biol., 40: 546-554.

Bouaziz, H.; Croute, F.; Boudawara, T.; Soleilhavoup, J. P. and Zeghal, N. (2007) : "Oxidative stress induced by fluoride in adult mice and their suckling pups". Experimental and Toxicologic Pathology, 58: 339-349.

Canfield, R. L.; Henderson, C. R.; Cory-Slechta, D. A.; Cox, C.; Jusko, T. A. and Lanphear, B. P. (2003) : "Intellectual impairment in children with blood lead concentrations below $10 \mathrm{~g}$ per deciliter". N.E.J.M., 348: 1517-1526.

Chen, J.; Zhu, W.; Chen, Q. and Lü, L. (2004): "Effects of lead on the Brn-3a expression and the apoptosis in hippocampus neurons". Journal of Hygiene $\operatorname{Re}-$ search, 33: 134-6,139. 
Chouhan, S.; Lomash, V. and Flora, S. J. S. (2009) : "Fluoride-induced changes in haem biosynthesis pathway, neurological variables and tissue histopathology of rats". J. Appl. Toxicol., 30: 63-73.

\section{Cooper, G. P; Suszkiw, J. B. and Man-} alis, R. S. (1984) : "Presynaptic effects of heavy metals", in: Narahashi,T.,(Ed.), Cellular and molecular neurotoxicology. New York, Raven Press, P.P.1-21.

Côté, A.; Silva, R. and Cuello, A. C. (1993) : "Current protocols for light microscopy immunocytochemistry", In: Cuello, A.C, (Ed.), Immunohistochemistry II, John Wiley \& Sons, Chichester, 147-168.

Doull, J.; Boekelheide, K.; Farishian, B.G.; Isaacson, R. L.; KIotz, J. B.; Kumar, J. V.; Limeback, H.; Poole, C.; Puzas, J. E.; Reed, N. M. R.; Thiessen, K. M. and Webster, T. F. (2006) : "Fluoride in Drinking Water: A Scientific Review of EPA's Standards". National Academies Press, Washington, DC, 23.

Ellman, G. L.; Courtney, K. D.; Andres, V. and Featherstone, R. M. (1961) : "A new and rapid colorimetric determination of acetylcholinesterase activity". Biochem. Pharmacol., 7: 88-95.

Garci'a-Arenas, G.; ClaudioL, Pe'rezSeveriano, F. and Ríos, C. (1999) : "Lead acetate exposure inhibits nitric oxide syn- thase activity in capillary and synaptosomal fractions of mouse brain". Toxicol. Sci., 50: 244-84.

Habal, R. (2002) : "Lead toxicity". Medicine, 11: 1-17,

Hong, J. H.; Ge, Y. M.; Ning, H. M. and Wang, J. D. (2005) : "Effects of high fluoride and low iodine on learning memory and AchE of brain in offspring rats". Chin. J. Prev. Med., 6: 489-91.

Lanshakov, D. A.; Bulygina, V. V.; Romanova, I. V. and Dygalo, N. N. (2009) : "Immunohistochemical analysis of active caspase- 3 expression in structures of neonatal brain". Bulletin of Experimental Biology and Medicine, 147: 635-8.

Li, Y. H.; Wang, W. Y; Yang, L. S. and Li, H. R. (2003) : "Environmental epidemic characteristics of coal burning endemic fluorosis and the safety threshold of coal fluoride in china". Fluoride, 36: 106-11.

Liu, J. S.; Xie, L. L.; Hong, A. and Chen, S. Q. (1999) : "Animal model for Alzheimer's disease based on the blockade of neuronal nicotinic acetylcholine receptors". Journal of Hygiene Research, 28: 218-20.

Liu, Q.; Xiao, T. T.; Zhang, R. and Niu, Y. J. (2010) : "Effects of prenatal exposure to lead on hippocampal nephroblastoma 
over-expressed gene expression of offspring". Chinese Journal of Industrial Hygiene and Occupational Diseases, 28:181-5.

Mabuchi, T.; Kitagawa, K,; Kuwabara, $K_{\text {; }}$ et al. (2001) : "Phosphorylation of cAMP Response element-binding protein in hippocampal neurons as a protective response after exposure to glutamate in vitro and ischemia in vivo". The Journal of Neuroscience, 21: 9204-9213.

Masters, R. D.; Coplan, M. J.; Hone, B. T. and Dykes, J. E. (2000) : "Association of silicofluoride treated water with elevated blood lead". Neurotoxicology, 21:10911100.

Menshanov, P. N.; Bannova, A. V. and Dygalo, N. N. (2006) : "Region-specific interrelations between apoptotic proteins expression and DNA fragmentation in the neonatal rat brain". Neurochem.Res., 31: 869-875.

Niu, R.; Sun, Z.; Cheng, Z.; Li, Z. and Wang, J. (2009) : "Decreased learning ability and low hippocampus glutamate in offspring rats exposed to fluoride and lead". Environmental Toxicology and Pharmacology, 28: 254-258.

Reddy, G. R.; Basha, M. R.; Devi, C. B.; Suresh, A.; Baker, J. L.; Shafeek, A.; Heinz, J. and Chetty, C. S. (2003) : "Lead induced effects on acetylcholinesterase activity in cerebellum and hippocampus of developing rat". Int. J. Devl. Neuroscience, 21: 347-352.

Selvín-Testa, A.; Loidl, C. F.; LópezCosta, J. J.; López, E. M. and PecciSaavedra, J. (1994) : "Chronic lead exposure induces astrogliosis in hippocampus and cerebellum". Neurotoxicology, 15 : $389-401$.

Selvin-Testa, A.; Lopez-Costa, J. J.; Nessi De Aviron, A. C. and Pecci Saavedra, J. (1991) : "Astroglial Alterations in Rat Hippocampus During Chronic Lead Exposure". G.L.I.A, 4: 384-392.

Shanthakumari, D.; Srinivasalu, S. and Subramanian, S. (2004) : "Effect of fluoride intoxication on lipid peroxidation and antioxidant status in experimental rats". Toxicology, 204: 219-228.

Sharifi, A. M.; Baniasadi, S.; Jorjani, M.; Rahimi, F. and Bakhshayesh, M. (2002) : "Investigation of acute lead poisoning on apoptosis in rat hippocampus in vivo". Neurosci. Lett., 329 (1): 45-48.

Shivarajashankara, X. M.; Shivashankara, A. R.; Bhat, G. P.; Rao, S. M. and Rao, S. H. (2002) : "Histological changes in rat brain of young fluoride intoxicated rats". Fluoride, 35: 12-21.

Sun, Z. R.; Liu, F. Z.; Wu, L. N.; Lü, Y. 
and Yu, D. K. (2000) : "Effects of high fluoride drinking water on the cerebral functions of mice". Chin. J. Endemiol., 19: 262263.

Tsakiris, S.; Angelogianni, P.; Schulpis, K. H. and Stavridis, J. C. (2000) : "Protective effect of L-phenylalanine on rat brain acetylcholinesterase inhibition induced by free radicals". Clin Biochem., 33 : 103-6.

Wang, J. D. (2007) : "Fluoride intoxication research", In:Wang, J.D. (Ed.), Study on Industrial Fluoride Pollution in Baotou. China Agriculture Press, Beijing, P.P. 50.

Wilkinson, J. H.; Baron, D. N.; Moss, D. W. and Walker P. G. (1972) : "standardization of clinical enzyme assays; a reference method for aspartate and alanine transaminase". J.Clin.Pathol., 25: 940944.

Wilson, B. W.; Padilla, S.; Henderson, J. D.; Brimijoin, S.; Dass, P. D., Elliot, G.; Jaeger, B.; Lanz, D.; Pearson, R. and Spies, R. (1996) : "Factors in standardizing automated cholinesterase assays". J. Toxicol. Environ. Health, 48: 187-195.

Wu, C.; Gu, X.; Ge, Y. M.; Zhang, J. and Wang, J. D. (2006) : "Effect of high fluoride and arsenic on brain biochemical indexes and learning-memory in rats". Fluoride, 39: 274-279.
Xiang, Q.; Liang, Y.; Chen, L.; Wang, C.; Chen, B.; Chen, X.; Zhouc. M. and Shanghai, P. R. (2003) : "Effect of Fluoride in drinking water on children's intelligence". Fluoride, 36: 84-94.

Yu, G. Y.; Yan, C. H.; Yu, X. G.; Zuo, Y.; Zou, X. X.; Wu, S. H.; Xu, J. and Shen, X. M. (2008): "Effects of moderate lead poisoning on the hippocampus tissue of rabbits in juvenile stage". Chinese Journal of Preventive Medicine, 42: $160-4$.

Yudkoff, M.; Nissim, I.; Nelson, D.; Lin, Z. P. and Erecinska, M. (1991) : "The glutamate dehydrogenase reaction as a source of glutamic acid in synaptosomes". J. Neurochem., 57: 153-160.

Zhang, M.; Wang, A.; He, W.; He, P.; $X u, B . ; X i a, T$.; Chen, $X$. and Yang, K. (2007) : "Effects of fluoride on the expression of NCAM, oxidative stress, and apoptosis in primary cultured hippocampal neurons". Toxicology, $236: 208-$ 16.

Zhang, Z.; Shen, $X$. and Xu, X. (2001) : "Effects of selenium on the damage of learning memory ability of mice induced by fluoride". Journal of Hygiene Research, 30: 144-146.

Zhang, J.; Zhu, W. J.; Xu, X. H. and Zhang, Z. J. (2010) : "Effect of fluoride on 
calcium ion concentration and expression of nuclear transcription factor kappa-B ?65 in rat hippocampus". Experimental and Toxicologic Pathology, 19 [Epub ahead of print].
Zhu, W.; Zhang, J. and Zhang, Z. (2011) : "Effects of fluoride on synaptic membrane fluidity and PSD-95 expression level in rat hippocampus". Biol. Trace Elem. Res.,139: 197-203. 


\title{
التأثيرات على القرن الإمونى لصغار الفئران الهسهمة بو اسطة الفلورايد و الرصاص الهون
}

\author{
المشتبركون فى البحث
ايريغسى عاطف فوزنى إيهان إبهاعيل حسن

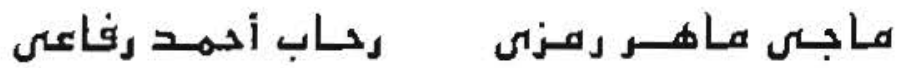 كلية الطب - جامعة المنيا

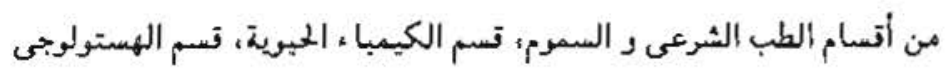

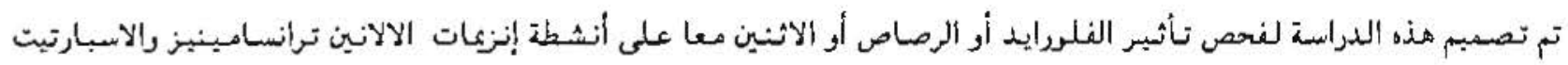

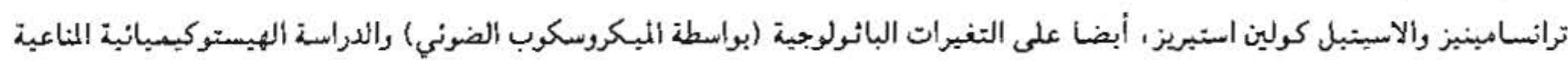

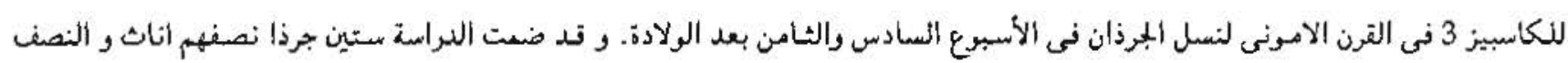

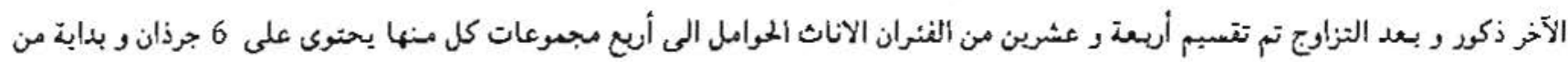

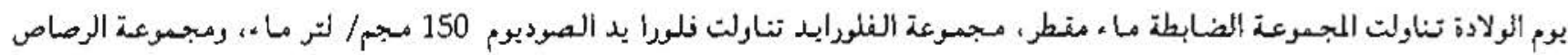

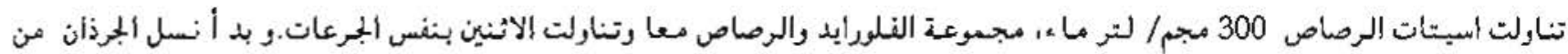

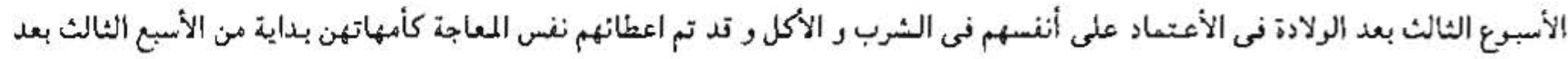

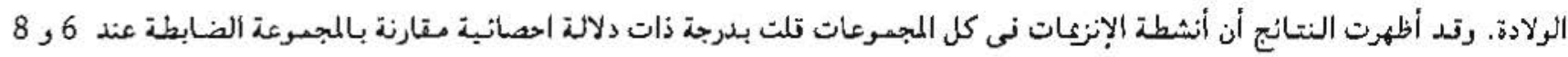

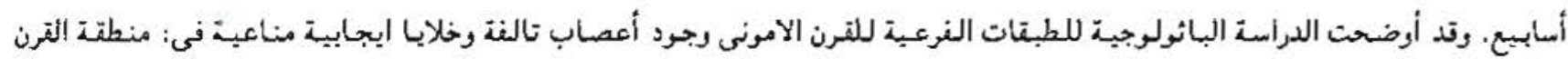

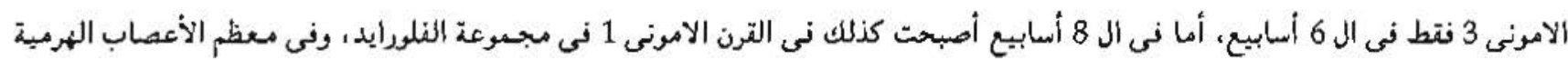

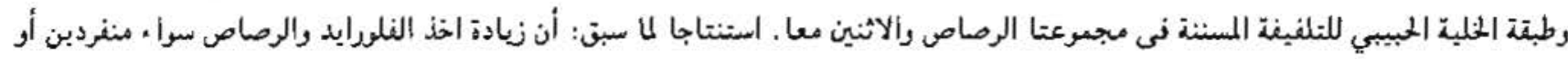
متحدين أثناء هراحل النمو المبكرة بؤثر على الترن الامونى كيموحبريا و باثثولوجيا رهيستوكيميانيا. 